\title{
Toward Integration between Total Quality Management \& Knowledge Management: Evidence from Libraries of Jordanian Universities
}

\author{
Othman Obeidat, Ghazi A. Al-Weshah, Marwan Nsour \\ Jordan
}

\begin{abstract}
The purpose of this study is to explore the benefits of employing total quality management and knowledge management principles in academic libraries in Jordan. Data about total quality management and knowledge management are obtained through a survey questionnaire distributed to employees in the academic libraries in Jordan. The study uses variance and correlation analysis. The study results indicate that total quality management processes affect knowledge management. Since this study is limited to the literature in academic libraries, caution must be considered in generalizing the results from this study to other situations in the service academic library environment. This study provides useful information and managerial implications for decision makers in the academic libraries in Jordan and other Arab countries. It also proposes new service practices for the academic library environment. This study attempts to bridge gaps in the literature between Arabian total quality management and knowledge management principles practices.
\end{abstract}

Keywords: Jordan, knowledge Management, Total Quality Management, Academic libraries, Universities.

\section{INTRODUCTION}

Knowledge management (KM) is an important administrative approach which connects cognitive investment with better results, both at the individual and the institutional levels. Hence, it confirms the link between knowledge and quality. Today, total quality is the goal sought by most institutions, but firms must translate the concepts of KM into tools and practices. Since knowledge generates wealth in the new economy, institutions must translate information into viable services through operations and strategies based on KM (Brancolini, 1992).

In an era of fast changes in the world in general and in the Arab countries in particular, a global financial and political crisis led to the collapse of world financial markets and many institutions. In Jordan, for example, some public and private sectors, including universities, are still struggling to survive and grow. As an important part of Jordan's national plan in higher education, universities and non-university libraries need to re-examine their rules and strategies for development. These universities (public and private) have so far focused on immediate profits and they now seek a formula for realization of quality in libraries through the Center of Excellence at the Yarmouk University.

An academic library is part of a service organization which delivers products personally to the customer. The primary purpose of the academic library is to support the teaching, research, and other academic programs of its parent organization (Begum, 2003). In the era of digital information, knowledge and quality in academic libraries are means of providing high value to end users with KM methodology (Al-Hadi, 2002). The importance of studying how quality affects society in an academic environment lies in that it is one of the pillars of any nation's economy and strategies, particularly of the national plan, which contribute to the national economy plan and system of the country. The university library has an active role in supplying the university with learning resources, education, and scientific research to help it in fulfilling its mission and achieve its objectives. Therefore, the university library occupies the place of the heart of the university, for without an efficient library there will be no successful university (Hinawi, 2008).

Therefore, when a crisis faces academic institutions, it becomes a matter of life or death for their institutions. In a service organization like an academic library, customer's satisfaction means fulfilling 
expectations. Librarians must find out what readers want and concentrate on providing it. The purpose of this study is to explore how the KM principles and total quality management (TQM) can help the Jordanian academic libraries in improving their overall performance.

\section{LITERATURE REVIEW}

Al-Samurai (2007) explained that the word 'quality' is derived from the Greek word Qualities which indicates the nature of a thing and its degree of righteousness. As far as libraries are concerned, quality may be identified as the services provided for users at a high level of excellence and the ability to meet the needs and wishes of users in line with their expectations, satisfaction, and happiness, for the right user in the right time and place. Total quality management (TQM) is one of the systems in place to meet the challenge of satisfying customers' needs and improving library's overall performance as it is based on the system of continuous improvement of performance at all levels of operation and management, and in all functional areas in the organization, using all human and financial resources available (Bruce \& Suzann, 1992). In this regard, Tobin (1990) indicated that TQM is the totally integrated effort for gaining competitive advantage by continuously improving every facet of the organizational culture. As highlighted by Oakland (1989), the TQM is an approach to improvement of the effectiveness and flexibility of business completely. It is an essential way of putting the entire process in order at every level, i.e., individual level, department level, and organizational level. Recently, Sivankalai and Thulasi (2012, p.67) clarified that TQM is a comprehensive and structured approach to organizational management that seeks to improve the quality of products and services through ongoing refinements in response to continuous feedback. Sivankalai and Thulasi (2012) stated that TQM is mainly concerned with continuous improvement in all work, from high level strategic planning and decision-making to detailed execution of work elements on the shop floor. It stems from the belief that mistakes can be avoided and defects can be prevented. It leads to continuously improving outcomes in all aspects of work, as a result of continuously improving capabilities, people, processes, technology, and machine capabilities.

The university libraries are viewed as an important part of the educational process integrated in universities. Hence, and for being one of the major tributaries of the information of interest to all its users, these libraries have to put the overall concept of quality management into practice to improve quality levels and enable the library to achieve excellence in services, which is the main objective of establishment of university libraries. Therefore, to improve and increase services and productivity of libraries, and to enjoy acceptance internationally, global institutions have consciously decided to apply total quality criteria in their day-to-day activities. In line with this, Pritchard (1996: 573) supported the application of comprehensive quality standards to those libraries. In addition, Nteka (1996) indicated that the evaluation of university libraries based on the amount of information on vessels has become a useless process. Further, the traditional view that improving the quality is inconsistent with increased productivity and that it contributes to increases in performance costs resulted in numerous administrative organizations in which libraries are reluctant to investment in the application of the TQM concept.

Total quality management has grown rapidly in recent years in public and private sectors with limited focus on libraries. Academic institutions including libraries have discovered that it is imperative to seek comprehensive quality to access global services. However, Hijazi (2006) indicated that the TQM system requires large efforts and long-term planning, like developing performance and continuous improvement benchmarks, teamwork, and exploitation of all available human and financial resources.

Saroja and Sujatha (2000) examined the application of TQM to the Library \& Information Science (LIS) Sector, with particular reference to Distance Education Libraries. Weng-Choong et al. (2009) examined the differences between Malaysian industrial and service organizations. Their results indicated that there is no significant difference between industrial and service organizations. This study has thus increased our understanding of the applicability of TQM practices and of the contribution of these applications in the sharing of knowledge, both in industrial and service organizations in Malaysia.

Sivankalai and Thulasi (2012) analyzed and evaluated the TQM in Academic Libraries with a view of examining the exposure of library professionals. Besides, their study aimed at highlighting the problems encountered by the professionals and suggesting some measures for their improvement. These authors investigated the professionals through a survey based on a structured questionnaire. Various statistical methods have been used for data analysis. 
Düren (2012) investigated some examples of quality management projects in Germany and explained the first steps of quality management in two academic libraries. Special attention was paid to a leadership style recommended when implementing TQM in libraries. Harith (2013) determined the indicators/criteria or measures for academic libraries in India. As a service organization, academic libraries are faced with the problem of satisfaction of library users and how to measure and evaluate their services.

In developing countries in general, and in the Arab environment in particular, Al-Musned (2000) conducted a study titled: 'Information technology and current trends in libraries and information centers'. He examined the trends in modern information technologies in libraries and information centers and their role in information services; technical operations and their impact on the sources of information, with a focus on electronic journals and e-books; ownership of resources and access to them; and the possibility of the use of electronic libraries and digital information. His study also addressed the role of specialist information in light of the identified trends. The study targeted the operations of the overall application of quality standards in libraries and research centers, which include restructuring of services in libraries and research centers, expansion of places and buildings of the libraries and research centers, and improvement and development of the types of indexing systems employed in libraries and research centers.

Al-Ghamdi (2006) investigated the extent of application of the concepts of TQM in the Central Library and branch libraries of King Abdul Aziz University (The Kingdom of Saudi Arabia (KSA)) in order to measure application of the TQM concepts and employees' attitudes towards it. The results showed that the level of application of the principles of TQM in the university main and secondary libraries, including the needs of the users, was high. However, the level of satisfaction of users with library services and facilities was average. In Jordan, Nagy (1998) carried out a study in Amman Private University to explore the views of deans of faculties, department heads, directors of departments, and students about application of TQM in the university. The results indicated that the level of satisfaction of Amman Private University students with equipment was high while meantime it was low in the case of the plans of study, academic staff, and internal regulations and instructions.

Fatemih et al. (2009) evaluated library services at the Islamic Azad University in Iran using a sample of 526 beneficiaries. The study was intended to assess the overall quality. The results indicated presence of statistically-significant differences between all services provided on the ground and the services expected by users; especially in public services, non-paper materials, staff, time, and information users. Johansen (2000) analyzed the theory of TQM. He clarified the theoretical similarities and differences between information management and KM, and then proposed a model for the processes of KM.

Gover (2010) conducted a study to recognize the importance of the indicators of quality in library services and their application in Tishreen University in Syria from the perspective of students. The study, in addition, attempted to test for significant differences in viewpoints of Tishreen University students depending on the college and class variables.

Al-Abbas (2002) discussed the concepts of quality in libraries and information centers and the concept of TQM, whose importance and principles revolve around a focus on work and continuous improvement and on collective cooperation, rather than inspection and competition. In addition, the study examined stages of TQM implementation, training on the elements of TQM, and the formation of teams to improve quality and create an appropriate organizational culture. The study of Al-Abbas (2002) is one of the closest studies to the main theme and goal of the present study (the application of comprehensive quality standards in Jordanian university libraries). So, the present study will benefit from that of Al-Abbas (2002) in the theoretical literature, as well as in practical aspects.

Al-Shaar (2008) indentified TQM standards in academic libraries in Jordan and demonstrated how much useful the concept of TQM in public and private universities libraries is. The study showed that there are significant differences between the responses of members of the study sample regarding the possible benefits of TQM in public and private libraries.

Al-Khalayleh (2010) attempted to find out the relationship between organizational culture and practice of TQM in public university libraries in Jordan using a sample of 321 workers in these libraries. The researcher used two questionnaires, one for organizational culture and another for TQM. 
The results showed that the degree of application of TQM was medium and that there is statisticallysignificant link between organizational culture and practice of TQM in libraries of public universities in Jordan.

In another local example, AL-Jaradat et al. (2012) investigated the concept and application of TQM in Jordanian university libraries and sought to understand the causes of, and reasons and justification for, its application. In line with this, the researchers developed a measurement tool to identify the requirements of the application and tested its applicability to university libraries.

The Study Aim The purpose of this study is to explore the benefits of employing total quality management and knowledge management principles in academic libraries in Jordan. More specifically, the study proposes a model that shows principles of TQM and Knowledge management $(\mathrm{KM})$ processes.

\section{The STUdy ModeL}

The present study employed a comprehensive quality management philosophy based on a number of modern management concepts that require certain grounding in all regulatory, administrative, and social structures and conditions, as well as profoundly changing cultures of institutions and all traditional methods and measures. The model of the current study includes two variables:

- Principles of TQM as the independent variable.

- Knowledge management (KM) processes as the dependent variable.

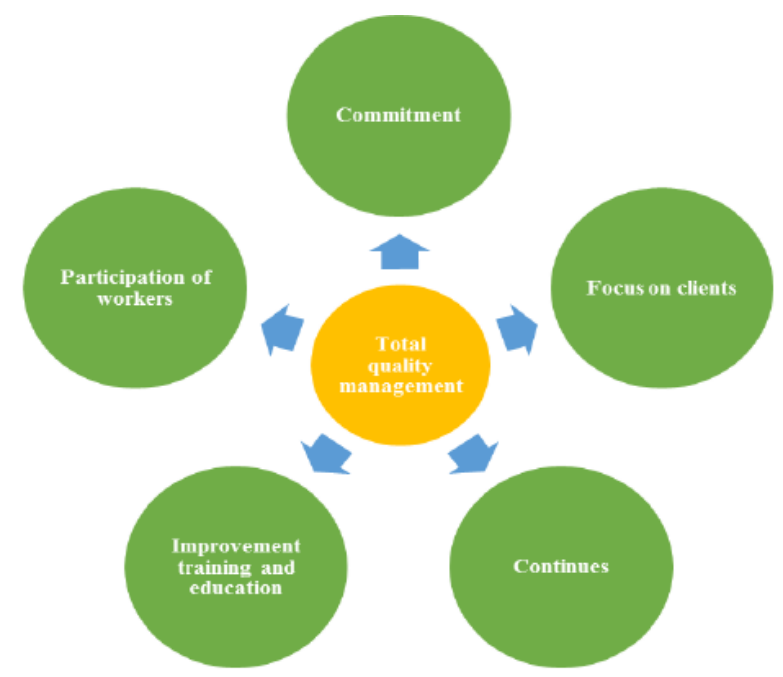

Figure1. TQM Principles Required for the Academic Library

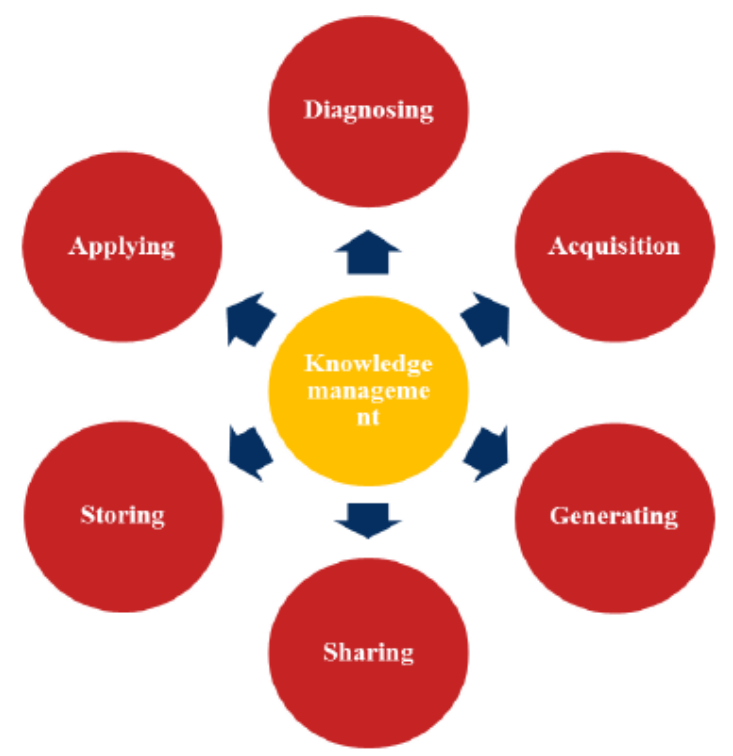

Figure2. Knowledge management (KM) processes required for the academic library 


\section{THE STUDY HYPOTHESES}

Based upon the previous studies and discussions, the following research hypotheses are raised and will be tested:

There are no statistically-significant relationships at the 0.05 level of significance $(\alpha=.05)$ between TQM and operations management (knowledge sharing, diagnosing knowledge, knowledge generation, knowledge acquisition, knowledge storing, and application of knowledge).

This main hypothesis can be fragmented into three secondary hypotheses as follows:

H1. There is no statistically-significant relationship at the 0.05 level of significance $(\alpha=.05)$ between TQM and diagnosing knowledge.

H2. There is no statistically-significant relationship at the 0.05 level of significance $(\alpha=.05)$ between TQM and knowledge acquisition.

H7. There is no statistically-significant relationship at the 0.05 level of significance $(\alpha=.05)$ between TQM and KM.

Previous studies have revealed a strong relationship between the joint use of KM and information technology. They have also revealed the importance of KM and learning in organizational success and performance (Riggs, 1992). In view of the above studies and discussions, the following research hypotheses are posed:

H3. There is no statistically-significant relationship between TQM and knowledge generation.

H4. There is no statistically-significant relationship between TQM and knowledge sharing.

H5. There is no statistically-significant relationship between TQM and knowledge storing.

H6. There is no statistically-significant relationship between TQM and knowledge application.

Although several studies have explored management issues in Arab countries, no study has yet been conducted about TQM and KM in the academic libraries in Jordan.

\section{Methodology}

The rapid developments in the academic environment and activities and the use of technology imparted further and further importance to quality and management. Diversity of tasks and breadth of the role played by academic libraries, the sources and systems, and digital databases heightened interest in the application of TQM as a scientific approach to successful management and a means for effective development and promotion of the level of performance. The quantitative approach of research in specific is employed in the current study. Additionally, correlation analysis is used to identify the relationship between TQM and KM. The current study employs different statistical analyses and tests including calculations of the means, percentages, standard deviations; correlation analysis; t-tests; and analysis of variance (ANOVA). On the other hand, instrument reliability analysis helped us identify the internal consistency of instrument items. In addition, regression analysis was used to determine the significant influence of the independent variable on the dependent variable.

The researchers developed a questionnaire particularly for the purpose of this study. The questionnaire was prepared at two stages:

1. A pilot test was conducted to ensure stability of the scale using a small sample of 33 individuals from the study sample who were selected randomly. After three weeks, the questionnaire was again administered to these 33 individuals and Pearson's correlation coefficient $(r)$ was used to determine the correlation between the two averaged responses. An $r$ value of 0.91 was obtained and it was considered as acceptable for this study. As the reliability of each dimension of this study is at least 0.75 , an overall high reliability can be expected.

2. This stage included the final description of the survey depending on the results of true and high persistence. The survey was also subjected to Cronbach's alpha test to ensure instrument reliability. A Cronbach's alpha coefficient of 0.98 was obtained, thus indicating high instrument reliability (Table 1). The final research instrument consisted of 52 paragraphs: 27 paragraphs for the dependent variables and 25 paragraphs for the independent variables. 
The researchers developed a list of 52 questions designed to assess application of TQM in the Jordanian academic environment. These questions were provided with a series of relevant statements and the respondents were asked to indicate the degree to which they agreed with each statement using a five-point Likert scale, with responses ranging from 'Strongly disagree' to 'Strongly agree'.

The study population consisted of employees in Jordanian public university libraries. The whole population comprises 237 employees. The sample consisted of managers and professionals working in these libraries, including Unit Managers, Assistant Unit Managers, Department Managers, Assistant Directors, Heads of Departments, Heads of Divisions, Chairmen of branches, and technical officers. The sample size was 117 , corresponding to about $49.4 \%$ of the whole population. The total number of full, retrieved questionnaires was 101 , corresponding to $42.6 \%$ of the study population and to a response rate of nearly $90.6 \%$. This response rate is acceptable and representative for the purposes of scientific research.

\section{Discussion OF THE RESUlts}

The questionnaire responses provided a wealth of information related to the research question and objectives. This section describes the basic features of the study based on the replies of the respondents in relation to the impact of KM on achievement of service quality. A correlation test was conducted and the results revealed a significant strong relationship between the dependent variables of the KM processes (knowledge acquisition, knowledge generation, knowledge sharing, storage of knowledge, the application of knowledge) and the independent variables of TQM principles ( $p=.000$ $<.05=\alpha)$.

Summarizing and compiling the results of literature review, after reviewing the literature showing that there is a difference and agreement among researchers on a number of knowledge management processes and overall quality, and these operations have been included in the discussion of the study.

These results demonstrate that there is a significant relationship between TQM principles and KM in the academic libraries in Jordan.

H.1. The study results indicate that there is a significant relationship between TQM and knowledge diagnosing. The ANOVA resulted in $F(1,82)=29.793$, which is greater than the indexed value of (3.97), $p=0.000$ at the 0.05 level of significance.

Table1. Instrument Reliability Test Results: TQM

\begin{tabular}{|l|l|l|l|l|}
\hline $\begin{array}{l}\text { Main } \\
\text { Variable }\end{array}$ & Sub-Variable & $\begin{array}{l}\text { Number of } \\
\text { Items }\end{array}$ & $\begin{array}{l}\text { Cronbach's } \\
\text { Alpha }\end{array}$ & $\begin{array}{l}\text { Items in the } \\
\text { Questionnaire }\end{array}$ \\
\hline $\begin{array}{l}\text { Total quality } \\
\text { management }\end{array}$ & Commitment & 5 & 0.775 & $28-32$ \\
\hline & Focus on clients & 4 & 0.845 & $33-36$ \\
\hline & Continuous improvement & 5 & 0.905 & $37-41$ \\
\hline & $\begin{array}{l}\text { Improvement training } \\
\text { and education }\end{array}$ & 5 & 0.890 & $42-46$ \\
\hline & Participation of workers & 6 & 0.915 & $47-52$ \\
\hline Total & $\mathbf{T Q M}$ & $\mathbf{2 5}$ & $\mathbf{0 . 9 6 0}$ & $\mathbf{2 8 - 5 2}$ \\
\hline
\end{tabular}

Table2. Instrument Reliability Test Results: KM

\begin{tabular}{|l|l|l|l|l|}
\hline Main Variable & Sub-Variable & Number of Items & Cronbach's Alpha & Items in the Questionnaire \\
\hline $\begin{array}{l}\text { Knowledge } \\
\text { management }\end{array}$ & Diagnosing & 5 & 0.851 & $1-5$ \\
\hline & Acquisition & 5 & 0.828 & $6-10$ \\
\hline & Generating & 4 & 0.802 & $11-14$ \\
\hline & Sharing & 6 & 0.869 & $15-20$ \\
\hline & Storing & 3 & 0.840 & $21-23$ \\
\hline & Applying & 4 & 0.823 & $24-27$ \\
\hline Total & Management & $\mathbf{2 7}$ & $\mathbf{0 . 9 5 3}$ & $\mathbf{1 - 2 7}$ \\
\hline
\end{tabular}

Regression analysis revealed that $R^{2}=0.267$, which indicates that the size of the explanatory power of this model is low (Table 3). The data analysis results (Table 4) show that $t$ is 5.458 and $p=0.000$. Therefore, the influence of knowledge diagnosing on TQM is statistically significant. Consequently, 
the null hypothesis is rejected and the alternative hypothesis is accepted. That is, there is a significant relationship between TQM and knowledge diagnosis. This process is considered the backbone of the knowledge management in academic libraries and basis of which is policy development, programs and other operations (Lang, 2001).

H.2. The analysis results highlight that there is a significant relationship between TQM and acquisition of knowledge. The ANOVA resulted in $F(1,82)$ of 54.356 , which is greater than the indexed value of (3.97), and a $p$ value of 0.000 at the 0.05 level of significance. Regression analysis uncovered that $R^{2}$ is 0.399 , which implies that the size of the explanatory power of this model is low (Table 3). Table 4 shows that the $t$ value is 5.458 and $p=0.000$. Therefore, the influence of TQM on knowledge acquisition is statistically significant. Hence, the null hypothesis is rejected and the alternative hypothesis is accepted, i.e., there is a significant relationship between TQM and knowledge acquisition.

H.3. The analysis outcomes underline that there is a significant relationship between TQM and knowledge generation. The ANOVA resulted in $F(1,82)$ of 41.934 , which is greater than the indexed value of (3.97), and a $p$ value of 0.000 at the level of significance of 0.05 . Regression analysis showed that $R^{2}=0.338$ (Table 3 ), which reveals that the size of the explanatory power of this model is low. As Table 4 shows, the $t$ value is 6.476 and $p=0.000$. As such, it is concluded that the influence of TQM on knowledge generation is statistically significant. The null hypothesis is thus rejected and the alternative hypothesis is accepted. In other words, there is a statistically-significant relationship between TQM and knowledge generation. Libraries realize that knowledge and management is not a goal, but a means to achieve the goals of libraries, and build on the specific goals of knowledge is put to operations other methods of knowledge such as: generation, storage, distribution, and application. (Heisig, \& Vorbeck, 2000). The generating knowledge is create, creativity and innovation of new knowledge, and including: (capturing, buying, creating, discovering, absorbing, acquiring)

H.4. The present study found that there is a statistically-significant relationship between TQM and knowledge sharing. The ANOVA resulted in an $F(1,82)$ value of 39.284 , which is greater than the indexed value of 3.97, and $p=0.000$ at the level of significance of 0.05 . Regression analysis disclosed that $R^{2}=0.324$, hence indicating that the size of the explanatory power of this model is low (Table 3 ). However, the results presented in Table 4 show that $t$ is 6.268 and $p=0.000$. In consequence, the influence of TQM on knowledge sharing is statistically significant. Accordingly, the null hypothesis is rejected and the alternative hypothesis is accepted. As study of (Gover, 2010) that there is a statistically-significant relationship between TQM and knowledge sharing.

H.5. The results of analysis in the present study point out that there is a significant relationship between TQM and knowledge storing. The ANOVA resulted in an $F(1,82)$ of 24.293 , which is greater than the indexed value of 3.97, and a $p$ value of 0.000 at the 0.05 level of significance 0.05 . Regression analysis revealed that $R^{2}=0.229$. This value discloses that the size of the explanatory power of this model is low (Table 3). In addition, the result presented in Table 4 bring to notice that $t$ has a value of 4.929 and $P=0.000$. Thus, the influence of TQM on knowledge storing was statistically significant. In light of this, the null hypothesis is rejected and the alternative hypothesis is accepted, which means that there is a statistically-significant relationship between TQM and knowledge storing, this mean maintain and sustain the data and search, access and retrieval, and include (keeping, sustainability, search, access, retrieval, warehousing) and the entire private library operations. (Sajeva, 2006, Garrick, 2000).

Table3. ANOVA Results

\begin{tabular}{|l|l|l|l|l|l|l|l|}
\hline Model & Sum of Squares & df & Mean & F & Sign & $\mathbf{R}^{\mathbf{2}}$ & $\mathbf{R}^{\mathbf{2}}(\mathbf{a d j})$ \\
\hline Knowledge diagnosis & 13.575 & 1 & 13.575 & 29.793 & 0.000 & 0.267 & 0.258 \\
\hline Knowledge acquisition & 20.305 & 1 & 20.305 & 54.356 & 0.000 & 0.399 & 0.391 \\
\hline Knowledge generating & 17.235 & 1 & 17.235 & 41.934 & 0.000 & 0.338 & 0.330 \\
\hline Knowledge sharing & 16.499 & 1 & 16.499 & 39.284 & 0.000 & 0.324 & 0.316 \\
\hline Knowledge storing & 11.642 & 1 & 11.642 & 24.293 & 0.000 & 0.229 & 0.219 \\
\hline Knowledge applying & 16.527 & 1 & 16.527 & 39.383 & 0.000 & 0.324 & 0.316 \\
\hline Knowledge management & 17.230 & 1 & 17.230 & 41.914 & 0.000 & 0.322 & 0.311 \\
\hline
\end{tabular}


Othman Obeidat et al.

Table4. Model Coefficients

\begin{tabular}{|l|l|l|l|l|l|}
\hline Model & $\begin{array}{l}\text { Unstandardized } \\
\text { B }\end{array}$ & $\begin{array}{l}\text { Coefficient } \\
\text { SE }\end{array}$ & $\begin{array}{l}\text { Standardized coefficient } \\
\text { Beta }\end{array}$ & $\boldsymbol{t}$ & Sign. \\
\hline Knowledge diagnosis & 0.468 & 0.860 & 0.516 & 5.458 & 0.000 \\
\hline Knowledge acquisition & 0.468 & 0.860 & 0.516 & 5.458 & 0.000 \\
\hline Knowledge generating & 0.547 & 0.840 & 0.582 & 6.476 & 0.000 \\
\hline Knowledge sharing & 0.467 & 0.750 & 0.569 & 6.268 & 0.000 \\
\hline Knowledge storing & 0.478 & 0.970 & 0.478 & 4.929 & 0.000 \\
\hline Knowledge applying & 0.511 & 0.820 & 0.570 & 6.276 & 0.000 \\
\hline Knowledge management & 0.583 & 0.900 & 0.582 & 6.474 & 0.000 \\
\hline
\end{tabular}

H.6. The current study concludes that there is a statistically-significant relationship between TQM and knowledge application. The ANOVA resulted in an $F(1,82)$ of 39.383 , which is greater than the indexed value of 3.97, and a $p$ of 0.000 at the 0.05 level of significance. The analysis also revealed that $R^{2}=0.324$, which means that the size of the explanatory power of this model is low (Table 3 ). The analysis outcomes (Table 4) show that $t$ is equal to 6.276 and $p$ equals 0.000 . Therefore, the influence of TQM on knowledge application is statistically significant. Consequently, the null hypothesis is rejected and the alternative hypothesis is accepted. That is to say, there is a statisticallysignificant relationship between TQM and knowledge application, related to objective and purpose of knowledge management is the application of knowledge available to the library, and include: (use, reuse, utilization, applying). Also Nagy (1998) carried out a study in Amman Private University to explore the views of deans of faculties, department heads, directors of departments, and students about application of TQM in the university.

H.7. The analysis results revealed that there is a statistically-significant relationship between TQM and KM. The ANOVA resulted in $F(1,82)$ of 41.914 , which is greater than the indexed value $(3.97)$, and a $p$ of 0.000 at level of significance of 0.05 . Regression analysis pointed out that $R^{2}=0.322$, thus indicating that the size of the explanatory power of this model is low (Table 3). Moreover, the results of data analysis presented in Table 4 reveal that $t$ has a value of 6.474 and $p=0.000$. Therefore, the influence of TQM on KM is statistically significant. In view of this finding, the null hypothesis is rejected and the alternative hypothesis is accepted, that is, there is a statistically-significant relationship between TQM and KM.

The foregoing results support earlier findings reported in the related literature in that there is a strong relationship between TQM and KM. Academic libraries are not expected to attain comprehensive quality without application of the principles of KM. The results of the current study revealed that there are statistically-significant correlations between TQM principles (adoption of quality and commitment of senior management, focus on users, continuous improvement, training and education, and employees' participation) and KM processes (diagnosis, acquisition, generation, sharing, storing, and application). Acquiring and applying knowledge are the most important processes to overall success of quality (Lawes, 1993; Mosher, 1979). The study results also confirm that the investigated public academic libraries do undertake substantive KM, but they do not have a culture of KM since most of the universities have applied the principles of total quality only as a ritual, not as a strategy for improving quality. This research paper can be a very useful source of information and impartial advice for decision makers in the academic libraries in Jordan and Arab countries. Further, this paper offers suggestions that may be helpful in developing adequate academic environment practices in Jordan and other Arab libraries.

\section{CONCLUSION AND RECOMMENDATIONS}

Based on the aforementioned, the current study concludes that there is statistically-significant relationship between TQM and knowledge diagnoses, knowledge acquisition, knowledge generation, knowledge sharing, knowledge storing, knowledge application, and the KM processes. Moreover, the expectations of users of a library have a critical effect on their perceptions of quality. It is vital to build and sustain a good reputation, which is important to users and library users. Also study of (Düren, 2012; Harith, 2013) assured that the service organization, academic libraries are faced with the problem of satisfaction of library users and how to measure and evaluate their services.

Al-Ghamdi (2006) showed that the level of application of the principles of TQM in the university main and secondary libraries, including the needs of the users, was high. However, the level of 
satisfaction of users with library services and facilities was average. In other respects, this study has few limitations. The study was limited to the public academic libraries in Jordan. Given this limited scope, caution must be exercised while generalizing the results drawn from the sample of this study to other academic libraries in other Arab countries. The current study investigated the relationship between TQM and KM in academic libraries of Jordanian public universities. Therefore, the study did not include libraries of the private sector or profit-orientation libraries in Jordan. Moreover, the current study did not consider the qualitative approach to analysis.

On the other hand, the researchers propose that future research should cover libraries in some other countries, both in the academic and non-academic environments. It has been well established that a link exists between the principles of TQM and the KM processes and how KM affects TQM in the academic libraries in Jordan. Therefore, two types of recommendations are given by the researchers: recommendations for practice and recommendations for future research.

\section{Recommendations for Practice}

- There is a need to create an environment that is conducive to the application of TQM as a permanent strategy rather than as a short-term plan through structural reconstruction of university. Moreover, attention should be paid to education and training on how to implement TQM and restructure the traditional methods and systems of work and begin using an integrated digital system of TQM that can contribute to reduced cost and improved higher education. Moreover, academic libraries should pay more attention to their institutional structures to encourage adoption of knowledge in their decision making as indicated in (Sivankalai and Thulasi, 2012) from high level strategic planning and decision-making to detailed execution of work elements on the shop floor. Academic libraries should focus on tacit knowledge, particularly knowledge in the minds of individuals, and appreciate the need to document it so that it becomes part of what is called organizational memory. Further, there is a need to bridge the gap between what the academic libraries have and what is actually needed, as inferred from existing knowledge. Furthermore, academic libraries should focus on informal contacts between staff and senior management to facilitate sharing of knowledge. as a result of continuously improving capabilities, people, processes, technology, and machine capabilities (Sivankalai and Thulasi, 2012). And WengChoong et al. (2009) assured that the applicability of TQM practices and of the contribution of these applications in the sharing of knowledge, both in industrial and service organizations in Malaysia.

- Customize and guide the type of media discourse about users and distribution of work and responsibilities within the system of TQM in the library.

- Academic libraries should continue to focus on the human resource as the primary element in accessing and sharing knowledge through an effective incentives system, which focuses on both material and moral aspects. Thus, academic libraries should focus on knowledge acquisition and application. This agreed with Hijazi (2006) indicated that the TQM system requires large efforts and long-term planning, like developing performance and continuous improvement benchmarks, teamwork, and exploitation of all available human and financial resources.

- Follow up the changing needs of users and the corresponding latest solutions and technologies. Additionally, perform surveys to compare the extent of the commitment of the Jordanian universities with the relevant public and private standards in the overall quality of programs in their libraries. Consequently, perceptions of employees of library criteria for the application of TQM and the extent to which they benefit in the event of a commitment to these standards should be improved.

\section{Recommendations for Further Research}

In light of the study limitations, further prospective studies related to TQM in libraries can be conducted, with particular emphasis on comparing the TQM practices between public and private libraries. Moreover, the proposed model in the study can be extended to include different service sectors. Methodologically, future studies can consider the qualitative approach to understanding the relationship between TQM and KM in quality of services in the libraries sector. 


\section{REFERENCES}

[1] Al-abbas, H. (2005). Measuring the quality of university library services: applied study on library services, King Abdulaziz University. Journal of King Fahd National Library, (111). (Source in Arabic).

[2] Al-Ghamdi, A. (2006). Application of the concept of total quality management in university libraries: An Empirical Study on the employer libraries King Abdul Aziz University in Jeddah. Unpublished Master's Thesis. King Abdul Aziz University, Jeddah.

[3] Al-Jaradat, O. Al-Momani, H. and Al-Hammouri, A. (2012) The extent of the application of quality management standards in Jordanian university libraries from the point of view of their employees. European Scientific Journal, (8) 22, 128-158.

[4] Al-Hadi, M. (2002). Total quality management for information facilities, recent trends in libraries and information. Journal of Management, 9 (17), 162. (Source in Arabic).

[5] Al-Khalayleh, I. (2010). Organizational culture and its relationship to the practice of total quality management in university libraries in Jordan from the point of view of employees. Unpublished Unpublished Master's Thesis. The University of Jordan.

[6] Al-Musned, S. (2000). Information technologies and current trends in libraries and information centers. Arabic Studies in Library and Information Science, 5 (3). (Source in Arabic).

[7] Al-Samurai, M. (2007), Total Quality Management in Production and Service Sectors, Amman: Dar Greer. (Source in Arabic).

[8] Al-Shaar (2008). The applicability of total quality management standards at academic libraries in Jordan. Unpublished Master's Thesis. Albalqa' Applied University, Al-Salt. (Source in Arabic).

[9] Begum, S. (2003) Total quality management in the academic library. Library Philosophy and Practice (e-Journal) 5(2), 1-3.

[10] Brancolini, K. (1992). Use and User Studies For Collection Evaluation, in: Branin Joseph (ed.) Collection Management for the 1990s (Chicago: American Library, Libraries, (54), 481-483.

[11] Babalhavaeji, F.: Moghaddam, A.; Aqili, S.; and Shakooii, A. (2009). Quality assessment of academic library performance: the case of an Iranian academic library. Malaysian Journal of Library \& Information Science, 14 (2), 51-81.

[12] Düren, P. (2012). Total Quality Management in academic libraries- best practices. Qualitative and Quantitative Methods in Libraries (QQML) 1: 43-50.

[13] Garrick, H. (2000). Research and knowledge at work: perspectives, case- studies and innovative strategies. Mast's thesis, Oxford University, London, UK.

[14] Retrieved June 16, 2011, from http://site.ebrary.com/lib/uoj/Doc.

[15] Gover, G. (2010). The extent of application of the quality of library services at the university from the point of view of students. Tishreen University Journal 2 (32), 30-49.

[16] Harith, M. (2013) Total Quality Management indicators in academic libraries: In India. Journal of Business Management \& Social Sciences Research, 2(11), 12-16.

[17] Heisig, P., \& Vorbeck, J. (2000). Knowledge best practices in Europe Springer verlag. Berlin, Germany: Heidelberger.

[18] Hijazi, H. (2006). Measuring the impact of understanding knowledge in Jordanians organizations: comparing public and private sectors to build a model to recruit knowledge. Unpublished Master's Thesis: Amman Arab University, Amman. (Source in Arabic).

[19] Hinawi, H. (2008). The development of Egyptian universities libraries in the light of the comprehensive quality management standards. Unpublished Ph.D Dissertation, University of Alexandria.

[20] Johannsen, C. (2000): . Total Quality Management in a Knowledge, Management Perspective. Journal of Documentation, 56 (1), 42-54.

[21] Lang, J. (2001). Managerial concerns in knowledge management. Journal of Knowledge Management, 5(1), 43-59.

[22] Lawes, A. (1993). The Benefits of Quality Management to the Library and Information Services Profession. Special Libraries, 84 (3), 6-4.

[23] Mosher, P. (1979). Collection Evaluation in Research Libraries: The Search for Quality, Consistency, and System in Collection Development. Library Resources and Technical Services, 23-17. (Source in Arabic). 
[24] Nagy, F. (1998). Total quality management and the potential applied in institutions of higher education: a case study. Master's Thesis: Yarmouk University, Irbid. (Source in Arabic).

[25] Nitecki, D. (1996). Changing the concept and measure of service quality in academic libraries. Journal of Academic Librarianship, 22, 181-190.

[26] Obeid, E. (2005). Apply the principles of total quality management in libraries and information centers. Research Published in the Forum Will be the Modern Methods for Managing Libraries and Information Centers in the Overall Quality. Alexandria, 18-20 December 2005. (Source in Arabic).

[27] Pritchard, S. M. (1996). Determining quality in academic libraries. Library Trends, (44), 572594.

[28] Riggs, D. (1992). TQM: Quality Improvement in New Clothes. College \& Research Libraries, 53 (6), 81-83.

[29] Sajeva, S. (2006). Empowering the potential of small and medium - sized enterprises. Challenges to implementation of knowledge management in small and medium sized enterprises. Retrieved from Journal of Social Sciences, 4(54), 241- 263

[30] Sivankalai, S and Thulasi, S. (2012). Total quality management in academic libraries. International Journal of Educational Research and Technology, 3(1), 66-72.

[31] Waks, S., and Frank, M. (1996). Application of the T.Q.M Approach Principle and the ISO 9000 Standards in Engineering Education. European Journal of Engineering Education, 24 (3), 249258.

[32] Weng-Choong, C., Keng-Boon, O., Pei, L., Yee-Loong, C. and Chen, Y. (2009). Total quality management and knowledge sharing: comparing Malaysia's manufacturing and service organizations. Journal of Applied Sciences, 9 (8), 1422-1431.

\section{AUTHORS' BIOGRAPHY}

Othman Obeidat, Head of Libraries and Information Management Department. And teaches with AlSalt College for Human Sciences at Al-Balqa' Applied University in Jordan. He has published on various subjects related to academic and digital libraries, with a focus on digital divide.

Ghazi A. Al-Weshah, is an Associate Professor of Marketing and Head of Marketing Department at the Faculty of Business, Al-Balqa Applied University- Jordan. Dr. Al -Weshah taught as a visiting assistant professor in 2012 for two semesters in joint MBA program between Florida Atlantic University and A-Baha University in Saudi Arabia. He was awarded his PhD in Marketing from The University of Wales- UK in 2010. Dr. Al-Weshah has published about 13 research papers in the field of marketing and management in international refereed journals.

Marwan Nsour, is a Professor of Management and former dean at the Faculty of Business, Al-Balqa Applied University- Jordan. Dr. Nsour has published many research papers in the field of management in international refereed journals. 